doi:https://doi.org/10.15407/emodel.40.06.101

UDC 004.412:519.237.5

N.V. Prykhodko, PhD, Economics, S.B. Prykhodko, Dr.Sci.Tech. Admiral Makarov National University of Shipbuilding (9, Heroes of Ukraine Ave., 54025, Mykolaiv, Ukraine Tel.: (0512) 424280, e-mail: university@nuos.edu.ua)

\title{
Constructing the Nonlinear Regression Models on the Basis of Multivariate Normalizing Transformations
}

The techniques to build the models, equations, confidence and prediction intervals of nonlinear regressions on the basis of multivariate normalizing transformations for non-Gaussian data are considered. The examples of application of the techniques for the four-dimensional non-Gaussian data set for two cases such as: univariate and multivariate normalizing transformations are given. The values of the multiple coefficient of determination such as: the mean magnitude of relative error and the percentage of prediction which are given are better for the nonlinear regression model for the Johnson multivariate transformation compared to the univariate one. The widths of the prediction interval of non-linear regression on the basis of the Johnson multivariate transformation are less than following Johnson univariate transformation for 26 of 30 rows of data. Approximately the same results are obtained for confidence intervals of nonlinear regression. In general, when constructing the models, equations, confidence and prediction intervals of non-linear regressions for multivariate non-Gaussian data, one should use multivariate normali- zing transformations. Normalizing data with univariate transformations instead of multivariate one may lead to increasing of width of the confidence and prediction intervals of non-linear regression.

$K$ e y w o r d s: non-linear regression model, prediction interval, normalizing transformation, multivariate non-Gaussian data.

Introduction. A normalizing transformation is often a good way to build models, equations, confidence and prediction intervals of nonlinear regressions [1-7]. However, well-known techniques for building models, equations, confidence and prediction intervals of non-linear regressions are based on the univariate normalizing transformations (such as log and Box-Cox transformations) which do not take into account the correlation between random variables in the case of normalization of multivariate non-Gaussian data. This leads to the need of using the multivariate normalizing transformations, which take into account the correlation to build models, equations, confidence and prediction intervals of nonlinear regression.

(C) N.V. Prykhodko, S.B. Prykhodko, 2018 
In this paper we demonstrate that there may be data sets for which the results of building the models such as confidence and prediction intervals of non-linear regressions depend on which normalizing transformation is applied, univariate or multivariate. We consider the techniques to build the models, confidence and prediction intervals of non-linear regression for multivariate non-Gaussian data. As and in [5] the techniques consist of three steps. In the first step a set of multivariate non-Gaussian data is normalized using a multivariate normalizing transformation. In the second step, the models, confidence and prediction intervals of linear regression for the normalized data are built. In the third step, the models, confidence and prediction intervals of non-linear regressions for multivariate non-Gaussian data on the basis of the models, confidence and prediction intervals of linear regression for the normalized data and the normalizing transformation are constructed.

Nonlinear regression model. In reference [2] authors define a nonlinear regression model as «a model for the relationship between a response and predictor(s) in which at least one parameter does not enter linearly into the model». According to $[1-3,6-8]$ the general nonlinear regression model may be represented as

$$
Y=f(\mathbf{x}, \boldsymbol{\theta})+\varepsilon
$$

where $f$ is a nonlinear function; $\mathbf{x}$ is a vector of regressors (independent variables); $\boldsymbol{\theta}$ is a vector of parameters; $\varepsilon$ is the error term that has the same properties as in linear regression, i.e. the Gaussian random variable which defines residuals, $\varepsilon \sim N\left(0, \sigma_{\varepsilon}^{2}\right)$.

We have additive error term in the model (1). According to [7, 8] the nonlinear regression model with multiplicative error term may be represented as

$$
Y=f(\mathbf{x}, \boldsymbol{\theta}) \varepsilon,
$$

where $\varepsilon \sim N\left(1, \sigma_{\varepsilon}^{2}\right)$.

Duncan [8] considered two models for the error structure: the additive form (1) and the multiplicative form (2) and simulated three distributions for $\varepsilon$ - the normal, the scale-contaminated normal, and the double exponential. In practice we will generally not know the form of the error term, but an additive error term undoubtedly is more common than multiplicative one. Bates and Watts [1] pointed out that the assumption of the additivity of the error is closely tied to the assumption of constant variance of the disturbances (residuals). It may be the case that the residuals can be considered as having constant variance, but as entering the model multiplicatively. In either case, one of the corrective actions is to take a transformation of the response (dependent variable). If the error is multiplicative, we can treat the nonlinear regression model as intrinsically linear 
and use the normalizing transformation [4]. That is, we define the nonlinear regression model as $Y=f(\mathbf{x}, \boldsymbol{\theta}, \varepsilon)$, where $\varepsilon \sim N\left(0, \sigma_{\varepsilon}^{2}\right)$.

The techniques. Consider bijective multivariate normalizing transformation of non-Gaussian random vector $\mathbf{P}=\left\{Y, X_{1}, X_{2}, \ldots, X_{k}\right\}^{T}$ to Gaussian random vector $\mathbf{T}=\left\{Z_{Y}, Z_{1}, Z_{2}, \ldots, Z_{k}\right\}^{T}$ is given by

$$
\mathbf{T}=\boldsymbol{\Psi}(\mathbf{P})
$$

and the inverse transformation for (3)

$$
\mathbf{P}=\boldsymbol{\Psi}^{-1}(\mathbf{T}) \text {. }
$$

The linear regression model for normalized data according to (3) will have the form [6]

$$
Z_{Y}=\hat{Z}_{Y}+\varepsilon=\bar{Z}_{Y}+\left(\mathbf{Z}_{X}^{+}\right) \hat{\mathbf{b}}+\varepsilon
$$

where $\hat{Z}_{Y}$ is prediction linear regression equation result for values of components of vector $\mathbf{z}_{X}=\left\{Z_{1}, Z_{2}, \ldots, Z_{k}\right\} ; \mathbf{Z}_{X}^{+}$is the matrix of centered regressors that contains the values $Z_{1_{i}}-\bar{Z}_{1}, Z_{2_{i}}-\bar{Z}_{2}, \ldots, Z_{k_{i}}-\bar{Z}_{k} ; \hat{\mathbf{b}}$ is estimator for vector of linear regression equation parameters, $\mathbf{b}=\left\{b_{1}, b_{2}, \ldots, b_{k}\right\}^{T} ; \varepsilon$ is the Gaussian random variable which defines residuals, $\varepsilon \sim N(0,1)$.

The nonlinear regression model will have the form

$$
Y=\psi_{Y}^{-1}\left[\bar{Z}_{Y}+\left(\mathbf{Z}_{X}^{+}\right) \hat{\mathbf{b}}+\varepsilon\right],
$$

where $\psi_{Y}$ is the first component of vector $\boldsymbol{\Psi}, \boldsymbol{\Psi}=\left\{\psi_{Y}, \psi_{1}, \psi_{2}, \ldots, \psi_{k}\right\}^{T}$. The technique to build a prediction interval of non-linear regression is based on a prediction interval of linear regression for normalized data, transformations (3) and (4):

$$
\psi_{Y}^{-1}\left(\hat{Z}_{Y} \pm t_{\alpha / 2, v} S_{Z_{Y}}\left\{1+\frac{1}{N}+\left(\mathbf{z}_{X}^{+}\right)^{T}\left[\left(\mathbf{Z}_{X}^{+}\right)^{T} \mathbf{Z}_{X}^{+}\right]^{-1}\left(\mathbf{z}_{X}^{+}\right)\right\}^{1 / 2}\right)
$$

where $S_{Z_{Y}}^{2}=\frac{1}{v} \sum_{i=1}^{N}\left(Z_{Y_{i}}-\hat{Z}_{Y_{i}}\right)^{2}, v=N-k-1 ;\left(\mathbf{Z}_{X}^{+}\right)^{T} \mathbf{Z}_{X}^{+}$is the $k \times k$ matrix

$$
\left(\mathbf{Z}_{X}^{+}\right)^{T} \mathbf{Z}_{X}^{+}=\left(\begin{array}{cccc}
S_{Z_{1} Z_{1}} & S_{Z_{1} Z_{2}} & \cdots & S_{Z_{1} Z_{k}} \\
S_{Z_{1} Z_{2}} & S_{Z_{2} Z_{2}} & \cdots & S_{Z_{2} Z_{k}} \\
\cdots & \cdots & \cdots & \cdots \\
S_{Z_{1} Z_{k}} & S_{Z_{2} Z_{k}} & \cdots & S_{Z_{k} Z_{k}}
\end{array}\right),
$$

where $S_{Z_{q} Z_{r}}=\sum_{i=1}^{N}\left[Z_{q_{i}}-\bar{Z}_{q}\right]\left[Z_{r_{i}}-\bar{Z}_{r}\right], q, r=1,2, \ldots, k$. 
A confidence interval of nonlinear regression is defined like (7) with the only difference that in the sum in curly brackets (7) there will not be 1:

$$
\psi_{Y}^{-1}\left(\hat{Z}_{Y} \pm t_{\alpha / 2, v} S_{Z_{r}}\left\{\frac{1}{N}+\left(\mathbf{z}_{X}^{+}\right)^{T}\left[\left(\mathbf{Z}_{X}^{+}\right)^{T} \mathbf{Z}_{X}^{+}\right]^{-1}\left(\mathbf{z}_{X}^{+}\right)\right\}^{1 / 2}\right)
$$

Examples. We consider the examples of building the models, equations, confidence and prediction intervals of nonlinear regressions for multivariate non-Gaussian data for two cases: univariate and multivariate normalizing transformations.

Table 1 contains the data on metrics of software for open-source Java-based system $[9,10]$. Recall that the first metric $Y$ involves actual software size in the thousand lines of code, the second $X_{1}$, third $X_{2}$ and fourth $X_{3}$ metrics determine respectively the total number of classes, the total number of relationships and the average number of attributes per class in conceptual data model. Table 1 also contains the lower bounds (LB) and upper bounds (UB) of the prediction intervals of nonlinear regressions, which calculation is considered below.

For normalizing the multivariate non-Gaussian data from Table 1, we use the Johnson univariate and multivariate transformations (the Johnson translation system) for $S_{B}$ family. In our case the Johnson normalizing translation is given by [11]:

$$
\mathbf{T}=\gamma+\boldsymbol{\eta} \mathbf{h}\left[\boldsymbol{\lambda}^{-1}(\mathbf{P}-\varphi)\right] \sim N_{m}\left(\mathbf{0}_{m}, \boldsymbol{\Sigma}\right),
$$

where $\mathbf{h}\left[\left(y_{Y}, y_{1}, \ldots, y_{k}\right)\right]=\left\{h_{Y}\left(y_{Y}\right), h_{1}\left(y_{1}\right), \ldots, h_{k}\left(y_{k}\right)\right\}^{T} ; h_{i}(\cdot)$ is one of the translation functions

$$
h= \begin{cases}\ln (y), & \text { for } S_{L}(\log \text { normal) family; } \\ \ln [y /(1-y)], & \text { for } S_{B} \text { (bounded) family; } \\ \operatorname{Arsh}(y), & \text { for } S_{U} \text { (unbounded) family; } \\ y, & \text { for } S_{N} \text { (normal) family. }\end{cases}
$$

Here $y=(X-\varphi) / \lambda$; $\operatorname{Arsh}(y)=\ln \left(y+\sqrt{y^{2}+1}\right)$. In our case $X$ equals $Y, X_{1}, X_{2}$ or $X_{3}$ respectively.

Parameters of Johnson univariate and multivariate transformations for $S_{B}$ family were estimated by the maximum likelihood method. Estimators for parameters of the univariate transformation (10) for metric $Y$ are: $\hat{\gamma}_{Y}=0,46387$; $\hat{\eta}_{Y}=0,50326 ; \hat{\varphi}_{Y}=2,817 ; \hat{\lambda}_{Y}=89,930$. Estimators for parameters of the multivariate transformation (9) for metric $Y$ are: $\hat{\gamma}_{Y}=9,6309 ; \hat{\eta}_{Y}=1,05243 ; \hat{\varphi}_{Y}=-1,4568$; $\hat{\lambda}_{Y}=153102,6$. Estimators for other parameters of the Johnson univariate and 
Table 1. Metrics of software and the prediction intervals of software size regressions

\begin{tabular}{|c|c|c|c|c|c|c|c|c|}
\hline \multirow{3}{*}{ No } & \multirow{3}{*}{ Y } & \multirow{3}{*}{$X_{1}$} & \multirow{3}{*}{$X_{2}$} & \multirow{3}{*}{$X_{3}$} & \multicolumn{4}{|c|}{ The bounds of the prediction intervals } \\
\hline & & & & & \multicolumn{2}{|c|}{ Univariate } & \multicolumn{2}{|c|}{ Multivariate } \\
\hline & & & & & LB & UB & LB & UB \\
\hline 1 & 11,717 & 8 & 6 & 4,25 & 5,679 & 22,412 & 7,536 & 19,277 \\
\hline 2 & 47,52 & 23 & 19 & 9,565 & 32,573 & 75,467 & 36,600 & 68,504 \\
\hline 3 & 84,01 & 26 & 40 & 11,462 & 77,736 & 91,114 & 73,863 & 96,264 \\
\hline 4 & 26,999 & 15 & 14 & 8,933 & 17,436 & 58,472 & 21,814 & 48,847 \\
\hline 5 & 41,72 & 20 & 15 & 5,9 & 20,726 & 63,360 & 25,763 & 54,772 \\
\hline 6 & 13,015 & 5 & 6 & 12,4 & 5,559 & 24,105 & 7,061 & 19,398 \\
\hline 7 & 30,402 & 18 & 7 & 6,611 & 11,701 & 46,283 & 14,924 & 36,873 \\
\hline 8 & 29,159 & 23 & 10 & 6,957 & 18,875 & 61,455 & 22,764 & 51,145 \\
\hline 9 & 53,443 & 28 & 25 & 4,179 & 40,607 & 80,655 & 45,398 & 77,523 \\
\hline 10 & 18,694 & 13 & 9 & 6,615 & 10,693 & 42,556 & 14,102 & 34,502 \\
\hline 11 & 26,384 & 16 & 6 & 5,125 & 9,052 & 37,791 & 11,900 & 30,337 \\
\hline 12 & 38,721 & 19 & 16 & 6,579 & 21,431 & 64,236 & 26,458 & 55,673 \\
\hline 13 & 75,643 & 26 & 30 & 6,154 & 49,028 & 83,854 & 52,398 & 82,637 \\
\hline 14 & 46,72 & 21 & 24 & 6,048 & 32,094 & 74,958 & 37,508 & 69,345 \\
\hline 15 & 6,413 & 7 & 5 & 4,143 & 4,920 & 18,108 & 6,290 & 15,899 \\
\hline 16 & 79,534 & 20 & 37 & 4,85 & 51,026 & 85,596 & 52,840 & 84,458 \\
\hline 17 & 36,343 & 18 & 17 & 5,333 & 20,068 & 62,454 & 25,536 & 54,455 \\
\hline 18 & 59,684 & 22 & 31 & 6,182 & 43,924 & 81,998 & 48,094 & 79,560 \\
\hline 19 & 50,454 & 15 & 20 & 11,6 & 25,246 & 70,052 & 29,796 & 61,411 \\
\hline 20 & 3,055 & 4 & 1 & 7 & 3,009 & 4,748 & 2,516 & 4,443 \\
\hline 21 & 63,257 & 34 & 17 & 3,971 & 45,506 & 84,384 & 44,137 & 78,697 \\
\hline 22 & 91,28 & 35 & 28 & 13,571 & 78,586 & 91,334 & 74,127 & 97,180 \\
\hline 23 & 32,707 & 11 & 17 & 7,545 & 15,088 & 54,334 & 19,782 & 45,949 \\
\hline 24 & 11 & 5 & 5 & 3,6 & 4,077 & 13,054 & 4,988 & 12,419 \\
\hline 25 & 5,543 & 6 & 4 & 3,833 & 4,203 & 13,643 & 5,062 & 12,421 \\
\hline 26 & 22,686 & 12 & 11 & 6,667 & 11,471 & 44,858 & 15,245 & 36,852 \\
\hline 27 & 3,911 & 3 & 2 & 6,667 & 3,048 & 5,105 & 2,834 & 5,520 \\
\hline 28 & 20,841 & 14 & 7 & 3 & 6,446 & 29,640 & 9,577 & 26,119 \\
\hline 29 & 9,269 & 6 & 5 & 3,5 & 4,360 & 14,963 & 5,483 & 13,826 \\
\hline 30 & 7,732 & 7 & 2 & 11,143 & 4,206 & 14,773 & 4,601 & 11,617 \\
\hline
\end{tabular}


Table 2. Estimators for parameters

\begin{tabular}{|c|c|c|c|c|c|c|c|c|}
\hline \multirow{2}{*}{$j$} & \multicolumn{4}{|c|}{ Univariate transformation } & \multicolumn{4}{c|}{ Multivariate transformation } \\
\cline { 2 - 9 } & $\hat{\gamma}_{j}$ & $\hat{\eta}_{j}$ & $\hat{\varphi}_{j}$ & $\hat{\lambda}_{j}$ & $\hat{\gamma}_{j}$ & $\hat{\eta}_{j}$ & $\hat{\varphi}_{j}$ & $\hat{\lambda}_{j}$ \\
\hline 1 & 0,38093 & 0,62689 & 2,634 & 33,711 & 15,5355 & 1,58306 & $-1,8884$ & 243051,0 \\
2 & 0,60545 & 0,62215 & 0,700 & 41,428 & 25,4294 & 2,54714 & $-6,9746$ & 311229,5 \\
3 & 0,65592 & 0,72789 & 2,839 & 11,780 & 0,72801 & 0,54312 & 3,2925 & 13,90 \\
\hline
\end{tabular}

multivariate transformations are in Table 2. The sample covariance matrix $\mathbf{S}_{N}$ of the $\mathbf{T}$ is used as the approximate moment-matching estimator of $\boldsymbol{\Sigma}$

$$
\mathbf{S}_{N}=\left(\begin{array}{llll}
1,0000 & 0,9514 & 0,9333 & 0,1574 \\
0,9514 & 1,0000 & 0,9006 & 0,1345 \\
0,9333 & 0,9006 & 1,0000 & 0,0554 \\
0,1574 & 0,1345 & 0,0554 & 1,0000
\end{array}\right) .
$$

For detecting the outliers in the data from Table 1 we use the technique based on multivariate normalizing transformations and the squared Mahalanobis distance (MD) $[12,13]$. There are no outliers in the data from Table 1 for 0,005 significance level and the Johnson multivariate transformation (9) for $S_{B}$ family. In $[9,10]$ it was also assumed that the data contains no outliers. The values of squared MD for normalized data by the Johnson univariate transformation (10) for $S_{B}$ family from Table 1 indicate the data of system 22 is multivariate outlier, since for this data row the squared MD equals to 17,73 is greater than the value of the quantile of the Chi-Square distribution, which equals to 14,86 for 0,005 significance level. Although note that without using normalization the data of system 11 is multivariate outlier since for this data row the squared MD equals to 15,44 .

After normalizing the non-Gaussian data, the linear regression model (5) is built

$$
Z_{Y}=\hat{Z}_{Y}+\varepsilon=\hat{b}_{0}+\hat{b}_{1} Z_{1}+\hat{b}_{2} Z_{2}+\hat{b}_{3} Z_{3}+\varepsilon
$$

Parameters of the linear regression model (11) were estimated by the least square method. Estimators for parameters of the model (11) for the Johnson univariate and multivariate transformation are: $\hat{b}_{0}=0 ; \hat{b}_{1}=0,46976 ; \hat{b}_{2}=0,53539$; $\hat{b}_{3}=0,11397$ and $\hat{b}_{0}=0 ; \hat{b}_{1}=0,56085 ; \hat{b}_{2}=0,42491 ; \hat{b}_{3}=0,05846$ respectively.

Next, the non-linear regression model (6) is built

$$
Y=\hat{\varphi}_{Y}+\hat{\lambda}_{Y}\left[1+e^{-\left(\hat{Z}_{Y}+\varepsilon-\hat{\gamma}_{Y}\right) / \hat{\eta}_{Y}}\right]^{-1}
$$


where

$$
Z_{j}=\gamma_{j}+\eta_{j} \ln \frac{X_{j}-\varphi_{j}}{\varphi_{j}+\lambda_{j}-X_{j}}, \varphi_{j}<X_{j}<\varphi_{j}+\lambda_{j}, j=1,2,3 .
$$

The model (12) becomes a nonlinear regression equation when there is no error term $\varepsilon$. A mean magnitude of relative error (MMRE) and percentage of prediction $(\operatorname{PRED}(0,25))$ are accepted as standard evaluations of prediction results by regression models and equations. The acceptable values of MMRE and $\operatorname{PRED}(0,25)$ are not more than 0,25 and not less than 0,75 respectively. The acceptable value of multiple coefficient of determination $R^{2}$ is approximately the same as for $\operatorname{PRED}(0,25)$. The values of $R^{2}, \operatorname{MMRE}$ and $\operatorname{PRED}(0,25)$, which equal 0,9672, 0,1389 and 0,8667 respectively, are better for the model (12) for the Johnson multivariate transformation in comparison with univariate one, for which these values are $0,9574,0,1579$ and 0,8000 respectively.

Table 1 contains the lower LB and upper UB bounds of the prediction intervals of nonlinear regressions, which calculated by (7) on the basis of the Johnson univariate and multivariate transformations respectively for 0,05 significance level. Note, the widths of the prediction interval of non-linear regression on the basis of Johnson multivariate transformation are less than following the Johnson univariate transformation for 26 rows of data: 1, 2, 4-19, 21, 23-26, 28-30. Approximately the same results are obtained for confidence intervals, which calculated by (8).

Following [14] multivariate kurtosis $\beta_{2}$ is estimated for the data from Table 1 and the normalized data on the basis of Johnson univariate and multivariate transformations for $S_{B}$ family. The estimator of multivariate kurtosis given by [14]:

$$
\hat{\beta}_{2}=\frac{1}{N} \sum_{i=1}^{N}\left\{\left(\mathbf{Z}_{i}-\overline{\mathbf{Z}}\right)^{T} \mathbf{S}_{N}^{-1}\left(\mathbf{Z}_{i}-\overline{\mathbf{Z}}\right)\right\}^{2} .
$$

In our case, in the formula (13), the vectors $\mathbf{Z}$ and $\overline{\mathbf{Z}}$ should be replaced by the vectors $\mathbf{P}$ and $\overline{\mathbf{P}}$ or $\mathbf{T}$ and $\overline{\mathbf{T}}$, respectively, for the initial (non-Gaussian) or normalized data. It is known that $\beta_{2}=m(m+2)$ holds under multivariate normality. The given equality is a necessary condition for multivariate normality. In our case $\beta_{2}=24$. The estimators of multivariate kurtosis equal 27,17, 32,05 and 24,02 for the data from Table 1, the normalized data on the basis of the Johnson univariate and multivariate transformations respectively. The values of these estimators indicate that the necessary condition for multivariate normality is practically performed for the normalized data on the basis of the Johnson multivariate transformation for family $S_{B}$, it does not hold for other data. 


\section{Conclusions}

In general, when constructing the models, equations, confidence and prediction intervals of non-linear regressions for multivariate non-Gaussian data, one should use multivariate normalizing transformations. Normalizing data with univariate transformations instead of multivariate one may lead to increasing of width of the confidence and prediction intervals of non-linear regression.

\section{REFERENCES}

1. Bates, D.M. and Watts, D.G. (1988), Nonlinear Regression Analysis and Its Applications, 2nd edition, John Wiley \& Sons, New York, USA, DOI: 10.1002/9780470316757.

2. Chatterjee, S. and Simonoff, J.S. (2013), Handbook of Regression Analysis, John Wiley \& Sons, New York, USA.

3. Drapper, N.R. and Smith, H. (1998), Applied Regression Analysis, John Wiley \& Sons, New York, USA.

4. Freund, Rudolf J., Wilson, William J. and Sa, Ping (2006), Regression analysis: statistical modeling of a response variable, 2nd edition, Elsevier Academic Press, Burlington, MA, London, GB.

5. Prykhodko, S.B. (2016), Developing the software defect prediction models using regression analysis based on normalizing transformations, Modern Problems in Testing of the Applied Software: The Research and Practice Seminar (PTTAS-2016), Poltava, Ukraine, May 25-26, 2016, pp. 6-7.

6. Ryan, T.P. (1997), Modern regression methods, John Wiley \& Sons, New York, USA, DOI: 10.1002/9780470382806.

7. Seber, G.A.F. and Wild, C.J. (1989), Nonlinear Regression, John Wiley \& Sons, New York, USA, DOI: $10.1002 / 0471725315$.

8. Duncan, G.T. (1978), An empirical study of jackknife constructed confidence regions in nonlinear regression, Technometrics, Vol. 20, no. 2, pp. 123-129, DOI: 10.2307/1268703.

9. Tan, H.B.K., Zhao, Y. and Zhang, H. (2006), Estimating LOC for information systems from their conceptual data models, Proceedings of the 28th International Conference on Software Engineering (ICSE '06), Shanghai, China, May 20-28, 2006, pp. 321-330, DOI: 10.1145/ 1134285.1134331.

10. Tan, H.B.K., Zhao, Y. and Zhang, H. (2009), Conceptual data model-based software size estimation for information systems, Transactions on Software Engineering and Methodology, Vol. 19, Issue 2, October 2009, Article no. 4, DOI: 10.1145/1571629.1571630.

11. Stanfield, P.M., Wilson, J.R., Mirka, G.A., Glasscock, N.F., Psihogios, J.P. and Davis, J.R. (1996), Multivariate input modeling with Johnson distributions, Proceedings of the 28th Winter simulation conference WSC'96, Coronado, CA, USA, December 8-11, 1996, ed. S. Andradyttir, K.J. Healy, D.H. Withers and B.L. Nelson, IEEE Computer Society Washington, DC, USA, pp. 1457-1464.

12. Prykhodko, S., Prykhodko, N., Makarova, L. and Pukhalevych, A. (2018), Application of the Squared Mahalanobis Distance for Detecting Outliers in Multivariate Non-Gaussian Data, Proceedings of 14th International Conference on Advanced Trends in Radioelectronics, Telecommunications and Computer Engineering (TCSET), Lviv-Slavske, Ukraine, February 20-24, 2018, pp. 962-965, DOI: 10.1109/TCSET.2018.8336353. 
13. Prykhodko, S., Prykhodko, N., Makarova, L. and Pugachenko, K. (2017), Detecting Outliers in Multivariate Non-Gaussian Data on the basis of Normalizing Transformations, Proceedings of the 2017 IEEE First Ukraine Conference on Electrical and Computer Engineering (UKRCON) «Celebrating 25 Years of IEEE Ukraine Section», May 29 -June 2, 2017, Kyiv, Ukraine, pp. 846-849, DOI: 10.1109/UKRCON.2017.8100366.

14. Mardia, K.V. (1970), Measures of multivariate skewness and kurtosis with applications, Biometrika, Vol. 57, Issue 3, pp. 519-530, DOI: 10.1093/biomet/57.3.519.

Received 17.09.18

\title{
Н.В. Приходько, С.Б. Приходько
}

\author{
ПОСТРОЕНИЕ НЕЛИНЕЙНЫХ РЕГРЕССИОННЫХ МОДЕЛЕЙ \\ НА ОСНОВЕ МНОГОМЕРНЫХ НОРМАЛИЗИРУЮЩИХ ПРЕОБРАЗОВАНИЙ
}

Рассмотрены методы построения моделей, уравнений, доверительных интервалов и интервалов прогнозирования нелинейных регрессий на основе многомерных нормализирующих преобразований для негауссовых данных. Приведены примеры применения методов для набора четырехмерных негауссовых данных в двух случаях: одномерного и многомерного нормализирующих преобразований Джонсона. Значения множественного коэффициента детерминации, средней величины относительной ошибки и процента прогнозирования для нелинейной регрессионной модели при многомерном преобразовании Джонсона лучше по сравнению с одномерным. Ширина интервала предсказания нелинейной регрессии на основе многомерного преобразования Джонсона меньше, чем после одномерного преобразования Джонсона для 26 из 30 строк данных. Приблизительно такие же результаты получены для доверительных интервалов нелинейной регрессии. В общем случае при построении моделей, уравнений, доверительных интервалов и интервалов прогнозирования нелинейных регрессий для многомерных негауссовых данных следует использовать многомерные нормализирующие преобразования. Применение одномерных преобразований вместо многомерных для нормализации таких данных может приводить к увеличению ширины доверительных интервалов и интервалов предсказания нелинейной регрессии.

Ключ в в ы е слов в: нелинейная регрессионная модель, интервал прогнозирования, нормализующее преобразование, многомерные негауссовые данные.

\section{Н.В. Приходько, С.Б. Приходько}

\section{ПОБУДОВА НЕЛІНІЙНИХ РЕГРЕСІЙНИХ МОДЕЛЕЙ НА ОСНОВІ БАГАТОВИМІРНИХ НОРМАЛІЗУЮЧИХ ПЕРЕТВОРЕНЬ}

Розглянуто методи побудови моделей, рівнянь, довірчих інтервалів і інтервалів прогнозування нелінійних регресій на основі багатовимірних нормалізуючих перетворень для негаусових даних. Наведено приклади застосування методів для набору чотиривимірних негаусових даних у двох випадках: одновимірного і багатовимірного нормалізуючих перетворень Джонсона. Значення множинного коефіцієнта детермінації, середньої величини відносної похибки і відсотка прогнозування для нелінійної регресійної моделі при багатовимірному перетворенні Джонсона краще в порівнянні з одномірними. Ширина інтервалу передбачення нелінійної регресії на основі багатовимірного перетворення Джонсона менше, ніж після одновимірного перетворення Джонсона для 26330 рядків даних. Приблизно такі ж результати отримано для довірчих інтервалів нелінійної регресії. 
У загальному випадку при побудові моделей, рівнянь, довірчих інтервалів і інтервалів прогнозування нелінійних регресій для багатовимірних негаусових даних слід використовувати багатовимірні нормалізуючі перетворення. Застосування одновимірних перетворень замість багатовимірних для нормалізації таких даних може призводити до збільшення ширини довірчих інтервалів і інтервалів передбачення нелінійної регресії.

Ключ ю в і сло в а: нелінійна регресійна модель, інтервал прогнозування, нормалізуюче перетворення, багатовимірні негаусові дані.

PRYKHODKO Natalia Vasilivna, PhD (economics), Assistant Professor at the Finance Department of Admiral Makarov National University of Shipbuilding, Ministry of Education and Science of Ukraine, graduated from the Nikolayev Shipbuilding Institute named after Admiral S.O. Makarov in 1986, received the PhD degree from the St. Petersburg State Academy of Economics \& Engineering in 1993, nostrified her PhD Diploma in Kharkiv State University of Economics in 1999. Sphere of scientific research: modeling of stochastic systems with the use of statistical approach, data processing, nonlinear regression analysis.

PRYKHODKO Sergiy Borisovich, Doctor of Sciences (D.Sc.) in Mathematical Modeling and Computational Methods, Professor and Head of the Department of Software of Automated Systems of Admiral Makarov National University of Shipbuilding, Ministry of Education and Science of Ukraine, graduated from the Nikolayev Shipbuilding Institute named after Admiral S.O. Makarov in 1981, received the D.Sc. degree from the V.M. Glushkov Institute of Cybernetics of NAS of Ukraine in 2013. Sphere of scientific research: modeling, identification and simulation of stochastic systems, data and signal processing, nonlinear regression analysis, signal recognition, empirical software engineering. 